\title{
Soil Burial Biodegradation of PLA/Hydrolysed Collagen/Silver Nanoparticles Bionanocomposites
}

\author{
PETRUTA PREDA ${ }^{1,4^{*}}$, MARIA RAPA ${ }^{2}$, ALEXANDRU NICOARA ${ }^{3}$, OANA TUTUNARU $^{1}$, \\ MARIOARA AVRAM ${ }^{1}$, ANTON FICAI ${ }^{4}$ \\ ${ }^{1}$ National Institute for Research and Development in Microtechnologies -IMT Bucharest, 126A Erou Iancu Nicolae Str., \\ 077190, Bucharest, Romania \\ ${ }^{2}$ Faculty of Material Science and Engineering, Politehnica University of Bucharest, 313 Splaiul Independentei, 060042, \\ Bucharest, Romania \\ ${ }^{3}$ Biogenetix, 68 Unirii Str., 077067, Petresti Village, Ilfov, Romania \\ ${ }^{4}$ Politehnica University of Bucharest, Faculty of Applied Chemistry and Materials Science, 1-7 Gh. Polizu, 011061, \\ Bucharest, Romania
}

\begin{abstract}
In this study we evaluated the degradation behaviour of some polymeric bionanocomposites based on polylactic acid (PLA), hydrolysed collagen (HC) and silver nanoparticles (AgNPs) obtained by melt processing, by exposure at soil action for 30 days and 60 days. The quantification of the bionanocomposites' degradability was investigated by the weight loss determination, evaluation of the morphology-Scanning Electron Microscopy (SEM) measurements and the thermal parameters by Differential Scanning Calorimetry (DSC) measurements. From the obtained results we can observe that the polymeric composites based on hydrolysed collagen has degraded.
\end{abstract}

Keywords: biodegradation, bionanocomposites, soil burial, hydrolysed collagen

\section{Introduction}

A few years ago, researchers were concerned about the synthesis of polymeric materials for various applications, at this moment, their attention is focused on the environmental problem issues involving them. Because synthetic polymeric materials have high molecular mass and higher number of aromatic rings, it makes them more resistant to the microorganisms attacks, therefore the accumulation of plastic waste in the biosphere is a serious problem of environmental pollution [1]. In the last half century, many synthetic polymers have been developed from fossil resources. Annually more than 150 million tons of synthetic polymers are produced. Although these polymers have excellent properties for practical applications, their high stability has led to a significant increase in the amount of waste [2].

Based on the current concerns about environmental and health protection, and the reduction of fossil resources' consumption, the relevant researches have been carried out for the production of biodegradable polymers systems, considered to be the best solution proposed in the waste management [3]. Nowadays, the researchers' interest has been focused on the synthesis and processing of biodegradable polymers for packaging industry having the reduction of fossil fuels and protection of environment as the main. It is known that about $50 \%$ of packaging products are obtained from fossil fuels plastic materials [4].

Polylactic acid (PLA) is a biodegradable, biocompatible and compostable polyester, which comes from renewable sources by the usually industrial bacterial fermentation process of carbohydrates from corn, potatoes, molasses and beets of sugar. PLA can be also produced by polycondensation of lactic acid (LA) or by ring-opening polymerization of lactide (the cyclic dimer of lactic acid) [5]. Nature Works LLC is the major producer of PLA and used the bacterial fermentation process for obtaining LA (which is then polymerized) [5, 6]. PLA exhibits unique properties such as excellent organoleptic characteristics, comparable to polyethylene terephthalate (PET) or polypropylene (PP) it is accepted as

\footnotetext{
*email: petruta.preda@imt.ro
} 
safety material by US Food and Drug Administration, as a good candidate for packaging applications $[4,7]$. PLA with high molecular weight $\left(\mathrm{M}_{\mathrm{w}} \geq 2.0 \times 10^{5} \mathrm{Da}\right)$ for commercial use is more resistant to environmental microorganism attack, so a long time is necessary for the material to degrade, while PLA with low molecular weight $\left(\mathrm{M}_{\mathrm{w}}<1.0 \times 10^{4} \mathrm{Da}\right)$ is susceptible for microorganism degradation [5].

The PLA erodes mainly by hydrolysis, the hydrolytic degradation is the start of its degradation. The hydrolysis mechanism randomly minced the PLA by water molecules diffusion into amorphous regions which then initiates the cleavage of the ester bonds, resulting in a decrease of molecular weight and release of soluble oligomers and monomers. PLA hydrolysis plays an important role in abiotic environmental degradation, well understood that environmental degradation is also influenced by other factors such as temperature, $\mathrm{pH}$, soil moisture and UV radiation [5, 8]. Therefore, the development of biodegradable polymeric materials is a major challenge for industry plastic materials in the packaging industry and even agriculture.

Due to the advantageous properties of proteins such as good gas barrier and low water vapour permeability make them good additives for the preparation of biodegradable polymeric composites for packaging. Proteins like casein, gelatine, collagen can serve to improve the polymer properties and the quality of the food packaging or can be used as active substances carriers [9]. Also, besides protein, it has been shown that degradation can be accelerated by adding into PLA matrix the hydrophilic groups such as $-\mathrm{COOH},-\mathrm{OH}$ and $-\mathrm{NH}_{2}$ from plasticizers, cellulose, starch, chitosan and enzyme [10, 11].

In the current study, we sought to improve the commercial PLA degradation properties by adding the hydrolysed collagen. The AgNPs presence into PLA matrix aimed to obtain antimicrobial properties, subsequently used for food packaging, but this study is not the subject in this manuscript. The biodegradability of polymeric bionanocomposites obtained was evaluated by soil burial.

\section{Materials and Methods}

\subsection{Materials}

Bionanocomposites based of PLA (INGEO Biopolymer 2003D, from NatureWorks LLC), Tributyl O-acetyl citrate (ATBC) (PROVIRON, Belgium), hydrolysed collagen (HC) (Sigma-Aldrich) and silver nanoparticles (AgNPs) (US NANOMATERIALS RESEARCH, INC.) were prepared by melt mixing in a Brabender Plastograph at $170^{\circ} \mathrm{C}$ and rotor speed of $40 \mathrm{rot} / \mathrm{min}$, for $10 \mathrm{~min}$. $\mathrm{HC}$ was introduced as $5 \mathrm{wt} . \%$ and $10 \mathrm{wt} . \%$ content, respectively while the silver nanoparticles content was maintained at 1 wt. $\%$ with respect to plasticized PLA. The samples were coded as follows: PLA/ATBC, PLA/HC5, PLA/HC5/Ag, PLA/HC10 and PLA/HC10/Ag. A ratio between polymeric matrix and plasticizer of 80:20 wt. \% was kept for all matrices. The melted bionanocomposites were pressed into films and sheets using a hot laboratory press at $175^{\circ} \mathrm{C}$ and 125 atm and 150 atm respectively.

The biodegradation of the samples was evaluated by burial in soil. A natural soil from landfills Glina of Bucharest, Romania was used.

\subsection{Evaluation of biodegradability}

\subsubsection{Weight loss determination}

The samples were buried in a natural active soil. This method is adapted from SR EN ISO 846/2000 (Plastics - Evaluation of the action of microorganisms). The soil was conditioned in Petri dishes by subsequently maintaining at $105^{\circ} \mathrm{C}$ for $4 \mathrm{~h}$. The water content was determined with the equation (1) [12]:

$$
\frac{\text { Water weigh (lost at drying ) }}{\text { Dry soil weigh }} \times 100=\text { Water content }(\%)
$$

Samples were cut into a circle form with $2 \mathrm{~cm}$ dimension and $1 \mathrm{~mm}$ thickness, conditioned at $37{ }^{\circ} \mathrm{C}$ for $24 \mathrm{~h}$ and kept in a desiccator at ambient temperature until the weight of each sample reached a constant value (about 48 h). Each polymeric sample was buried from 30 days and 60 days respectively, 
in ambient conditions at about $25^{\circ} \mathrm{C}$ and $40 \%$ humidity (vertically in $200 \mathrm{~g}$ active soil and the thickness of the covering layer of the samples should not be bigger than $12.5 \mathrm{~cm}$ ). The specimens were removed and washed with water: ethanol (70:30), then were conditioned under the same conditions as before being buried in the soil. The biodegradation of the polymeric blends was evaluated by the weight losses determination of the samples in relation to the weight of the unexposed polymeric blends. Weight loss was calculated with equation (2)[12].

$$
\frac{W i-W f}{W i} \times 100=\text { Weight loss }(\%)
$$

where: $\mathrm{W} i$ - the initial weigh of samples; $W f$ - the weight of samples after buried in soil

Also, egg-carton specimens were tested, considered as a positive biodegradation test (cardboard).

\subsubsection{Differential Scanning Calorimetry (DSC) measurements}

The stability at soil burial biodegradation of the materials was evaluated also by thermal analysis DSC with a METTLER TOLEDO (Model DSC 823e, Switzerland) calorimeter. Samples were heated from ambient temperature up to $170{ }^{\circ} \mathrm{C}$ at a heating rate of $10{ }^{\circ} \mathrm{C} / \mathrm{min}$. DSC parameters were processed using the STARe 9.10 software from Mettler-Toledo. Following thermal characteristics: glass transition temperature (was taken at the midpoint of heat capacity changes, $\mathrm{T}_{\mathrm{g}}$ ), cold crystallization temperature, $\mathrm{T}_{\mathrm{cc}}\left({ }^{\circ} \mathrm{C}\right)$, cold crystallization enthalpy, $\Delta \mathrm{H}_{\mathrm{cc}}\left(\mathrm{J} \mathrm{g}^{-1}\right)$, melting temperature, $\mathrm{T}_{\mathrm{m}}\left({ }^{\circ} \mathrm{C}\right)$ and melting enthalpy, $\Delta \mathrm{H}_{\mathrm{m}}\left(\mathrm{J} \mathrm{g}^{-1}\right)$ were determined. Indium was used as calibration standard $\left(\mathrm{T}_{\mathrm{m}, \mathrm{onset}}=\right.$ $\left.156.6{ }^{\circ} \mathrm{C} ; \Delta \mathrm{H}_{\mathrm{m}}=28.95 \mathrm{~J} \mathrm{~g}^{-1}\right)$. The degree of crystallinity $\mathrm{X}_{\mathrm{c}}(\%)$ of the samples was also determined according to the equation (3):

$$
X_{c}=\left(\Delta H_{m} / \Delta H_{m}{ }^{0} \times w t . \%\right) \times 100
$$

where: $\Delta H_{m}{ }^{0}$ is the theoretical heat of fusion for a fully crystalline material and wt. \% is the weight fraction of PLA $\left(93.1 \mathrm{~J} \mathrm{~g}^{-1}\right)$ [13].

\subsubsection{Scanning Electron Microscopy (SEM) analysis}

Surface morphology study by SEM analysis was performed after biodegradation test using a Nova NanoSEM 630 (FEI Company) SEM microscope at an accelerating voltage of $2 \mathrm{kV}$ and a working distance of about $5 \mathrm{~mm}$. Before the SEM analysis the samples were coated with a $\sim 5 \mathrm{~nm}$ of thick gold thin layer.

\section{Results and discussions}

In our study, it was observed that the egg-carton positive control (cardboard) presented a rapid biodegradation rate, after the 60 days it obtained a degradation percentage of more than 50\% (Figure 1). This is attributed to cellulose, which is a susceptible natural polymer at degradation. Polymers biofragmentation is mainly determined by enzymes such as celluloses, amylases and chitinases which are frequently synthesized by soil microorganisms, which can hydrolyzed natural polymers (e.g., cellulose, starch, chitosan, chitin) [14-16].

After 60 days of soil exposure it was observed for PLA and PLA/ATBC specimens that not show any weight loss. Although, PLA is a biodegradable polymer, it is less susceptible to the soil microflora action. It is known from the literature that this material is hardly degradable compared to other biodegradable polymers [6]. According to other soil biodegradation studies, the PLA revealed that its degradation was not observed after 6 weeks, this process requiring a long time for initiation [17]. Also, in a recent soil burial biodegradation study for PLA and PLA/ATBC with chitosan (CS), was not observed degradation for PLA sample, in period of 50-150 days of testing, and for sample PLA/ATBC was reported about $1.75 \%$ weight loss after 50 days and $3.5 \%$ after 150 days, probably due to the loss of plasticizer. Also, the authors reported by SEM examination for PLA sample the presence of 
numerous cracks but with the kept its integrity, after 150 days of degradation [18]. So, rate of degradation is really time dependent and also could be influenced by microflora and chemical parameters of soil studied, when we talk about the obtained results for plasticized PLA, which was 0\% weight loss, after 60 days of soil burial. The sample studied by Vasile et al. (2018) based of PLA/ATBC and 5\% CS, after 150 days of degradation showed about the same results with our PLA/ATBC and PLA/HC 5 samples, after 60 days of soil burial test, approximatively $3 \%$ weight loss [18].

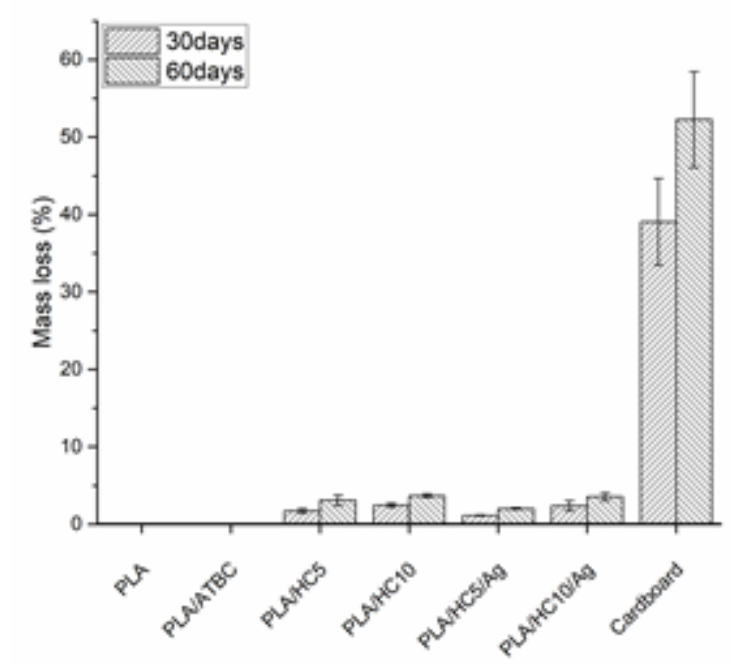

Figure 1. Mass loss of polymeric specimen at the end test period

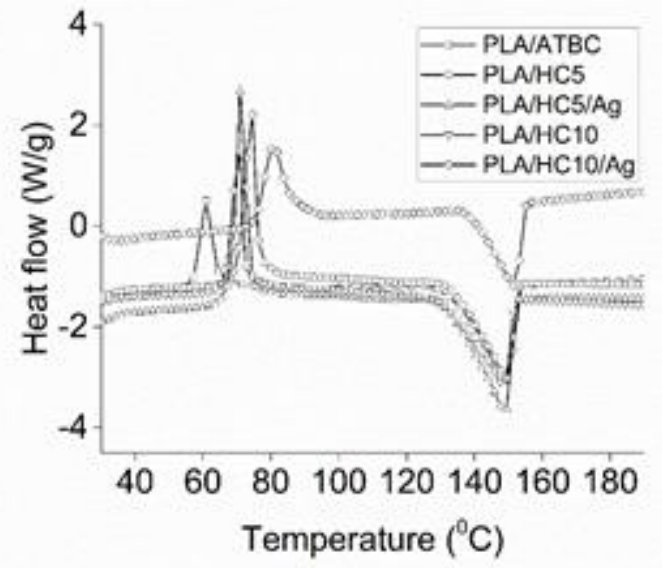

Figure 2. DSC thermograms of composites films, before of soil burial degradation study

From the burial soil biodegradation study, it was also observed that the increased collagen content $(10 \%)$ induces a higher degradation percentage, instead the incorporation of silver nanoparticles into the matrix does not significant changes by biodegradable properties of the materials. Thus, the samples PLA/HC10 and PLA/HC10/Ag showed a degradation of 3.7\% and respectively $3.55 \%$. Other studies have shown the degradation improved of PLA by adding fruit fibres into the matrix, were the rate of degradation was $37.4 \%$ after 8 weeks of soil burial [19]. Yang et al. (2004), also reported the biodegradation improve of PLA by collagen adding [20].

The DSC measurements were used to evaluate the possible changes in thermal properties for polymeric blends after soil biodegradation. Because the polymeric mixtures exposure to degradation by soil burial had a better degradation at 60 days, the DSC measurement was performed for this period and the curves are shown in Figure 2 and Figure 3. The DSC parameters for the composites before and after soil burial biodegradation are showed in table 1.

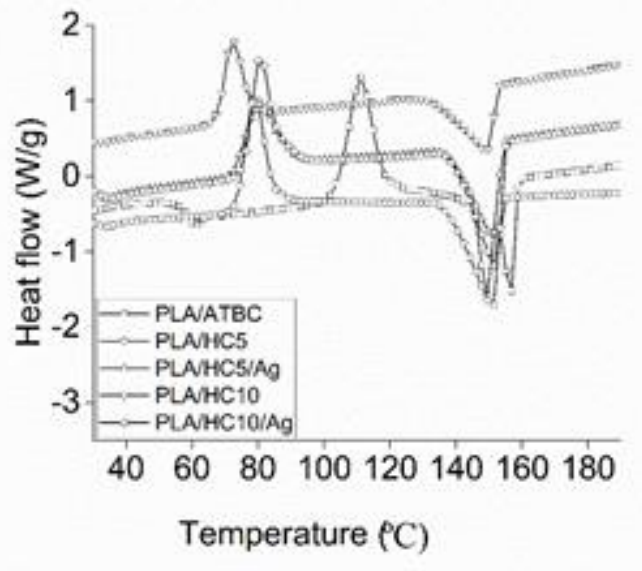

Rev. Chim., 71 (4), 2020, 128-135

\author{
Figure 3. DSC \\ thermograms of \\ composites films, \\ after 60 days of soil \\ burial degradation study
}


According to DSC analysis, before burial test, it was noticeable that the PLA had a lower Tg (34.5 ${ }^{\circ} \mathrm{C}$ ) by adding the plasticizer (ATBC), compared with neat PLA $\left(57.4{ }^{\circ} \mathrm{C}\right)$; this means that the segmental mobility of plasticized PLA in the amorphous phase increased.

Table 1. The dsc parameters for initially and after 60 days of soil burial

\begin{tabular}{|c|c|c|c|c|c|c|}
\hline Sample & $\begin{array}{l}\text { Tg, (midpoints) } \\
\left({ }^{\circ} \mathrm{C}\right)\end{array}$ & $\begin{array}{l}\mathrm{DHcc} \\
(\mathrm{J} / \mathrm{g})\end{array}$ & $\begin{array}{l}\text { Tcc } \\
\left({ }^{\circ} \mathrm{C}\right) \\
\end{array}$ & $\begin{array}{l}\mathrm{DHm} \\
(\mathrm{J} / \mathrm{g})\end{array}$ & $\begin{array}{l}\mathrm{Tm} \\
\left({ }^{\circ} \mathrm{C}\right) \\
\end{array}$ & $\begin{array}{l}\text { Xc, PLA } \\
(\%)\end{array}$ \\
\hline Neat PLA & 57.4 & 31.9 & 114.9 & 29.6 & $\begin{array}{l}150.1 \\
156.2\end{array}$ & 31.8 \\
\hline PLA/ATBC20 & 34.5 & 15.6 & 61.2 & 33.5 & 149.1 & 45.0 \\
\hline $\begin{array}{l}\text { PLA/ATBC20- } 60 \\
\text { days }\end{array}$ & 57.5 & 31.3 & 111.0 & 29.2 & $\begin{array}{l}156.3 \\
149.1 \\
\end{array}$ & 39.2 \\
\hline PLA/HC 5 & 33.4 & 22.3 & 74.0 & 31.1 & 149.7 & 44.0 \\
\hline PLA/HC 5- 60 days & 40.4 & 28.6 & 79.1 & 31.5 & 150.9 & 44.5 \\
\hline PLA/HC5/Ag & 36.6 & 22.4 & 71.5 & 32.7 & 149.0 & 46.7 \\
\hline $\begin{array}{l}\mathrm{PLA} / \mathrm{HC} 5 / \mathrm{Ag}-60 \\
\text { days }\end{array}$ & 32.6 & 24.4 & 80.4 & 29.6 & 150.8 & 42.3 \\
\hline PLA/HC 10 & 31.9 & 20.4 & 70.0 & 29.3 & 148.6 & 43.7 \\
\hline PLA/HC 10- 60 days & 44.8 & 19.0 & 72.7 & 27.0 & 149.1 & 40.3 \\
\hline PLA/HC10/Ag & 29.6 & 17.2 & 73.9 & 23.6 & 150.2 & 35.6 \\
\hline $\begin{array}{l}\text { PLA/HC10/Ag - } 60 \\
\text { days }\end{array}$ & 33.2 & 24.4 & 80.8 & 28.8 & 151.6 & 43.4 \\
\hline
\end{tabular}

Also, the introduction of HC into PLA matrix led to a further decrease of $\mathrm{Tg}$, to $31.9^{\circ} \mathrm{C}$ in the case of PLA/HC10 biocomposite leading to the high interaction between components involving the amorphous component of PLA matrix hindering the crystallization process. By adding $1 \%$ AgNPs into PLA composites a more pronounced effect of perturbing the lattice structure of PLA was registered. The crystallinity degree of PLA bionanocomposites showed the high range of values $(46.7 \%$ for PLA/HC5/Ag and $35.6 \%$ for PLA/HC10/Ag).

The materials studied in this research with lower $\mathrm{Tg}$ are more feasible due to the amorphous regions found, and showed a good degradation after 60 days of soil burial exposure. It is known from the literature that the polymers with a high degree of amorphous regions are more susceptible to degradation [3].

So, that at the end of the degradation test in soil, the DSC measurements indicated for all blends the $\mathrm{Tg}$ increased in comparison with the unexposed samples. The other authors also reported the $\mathrm{Tg}$ increased after soil burial of polylactic acid-based composites, with $\sim 2-4^{\circ} \mathrm{C}$ as the result of the degradation of the amorphous fraction and the crystalline domains increased during the degradation process [18]. Hence, while the collagen-based materials showed an increase in degradation due to loss of collagen, and lower Tg proves it more susceptible to soil microflora, and results were correlated with loss of mass values.

After biodegradation test, the evident Xc increase was observed in the case of PLA/HC10/Ag (43.4\%). Also, from table 1 , could be observed that the melting enthalpies $\left(\Delta H_{m}\right)$ of PLA composites increased favouring the crystallinity.

The scanning electron microscope (SEM) images relevel the surfaces morphology before and after 60 days of soil degradation of the PLA/ATBC, PLA/HC10 and PLA/HC10/Ag (it is shown in Figure 4).

The PLA/ATBC sample had smooth surface and sample kept its integrity after 60 days of degradation. Before degradation, the surface of PLA/HC10 and PLA/HC10/Ag is also smooth (figure 4A), but after 60 days irregularity surfaces were observed, that seems that the samples start to disintegrate, clearly indicated the degradation of samples (Figure $4 \mathrm{~B}$ and C). Also, after soil burial 
biodegradation, it was observed the interior appearance of the composites, with porous aspect (figure 4C).

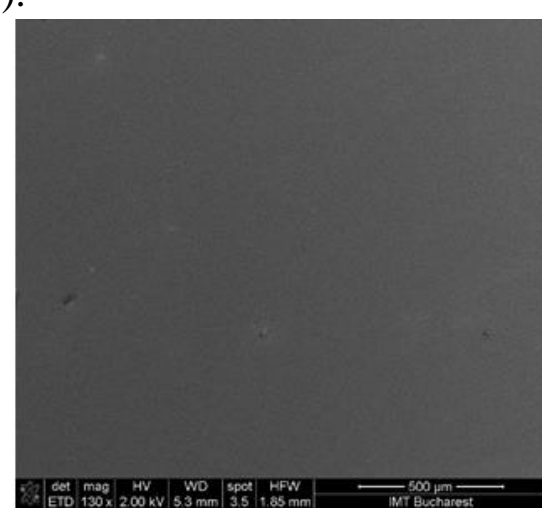

Figure 4A -PLA/ATBC

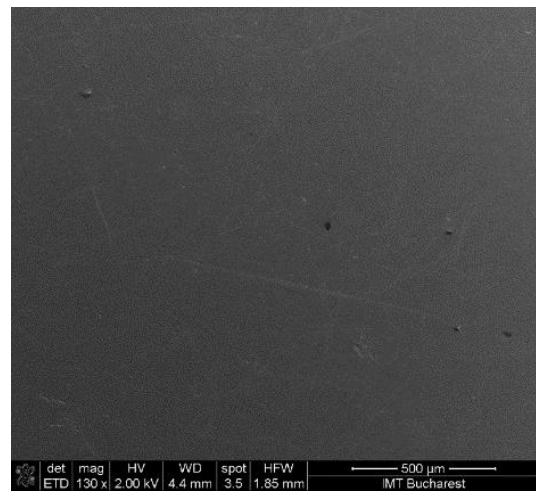

Figure 4B-PLA/ATBC

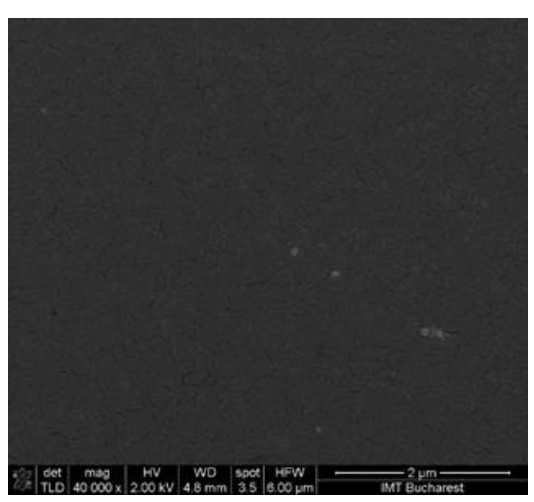

Figure 4C-PLA/ATBC

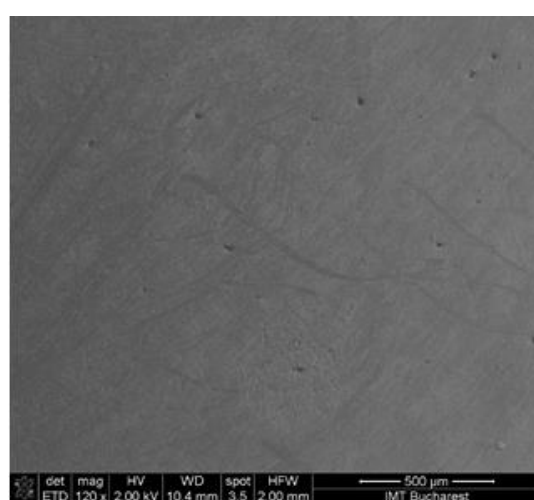

Figure 4A-PLA/HC10

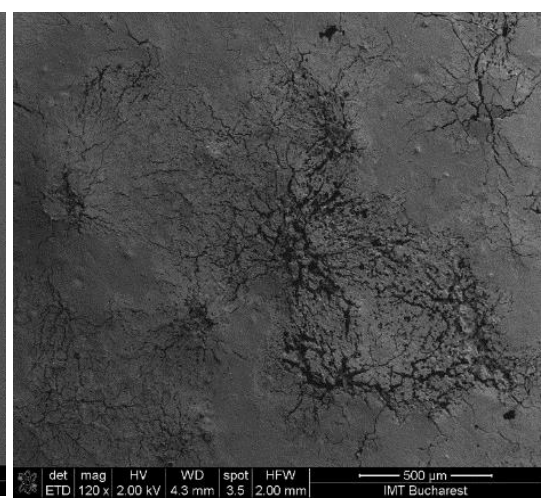

Figure 4B-PLA/HC10

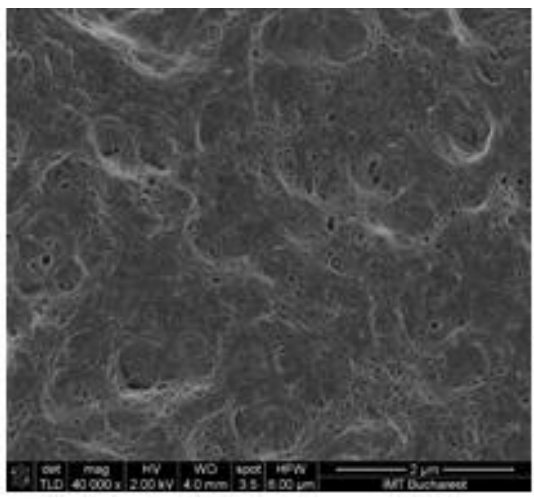

Figure 4C-PLA/HC10

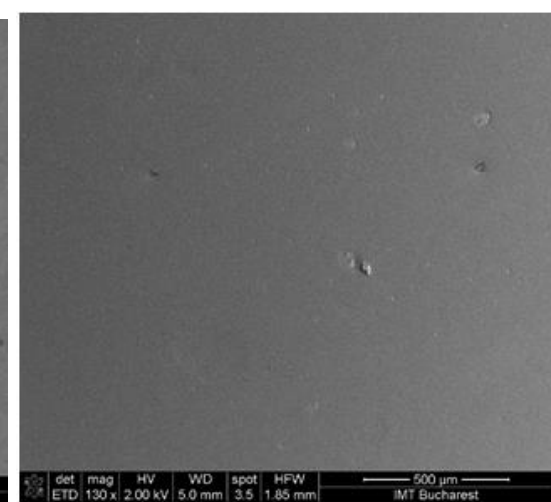

Figure 4A-PLA/HC10/Ag

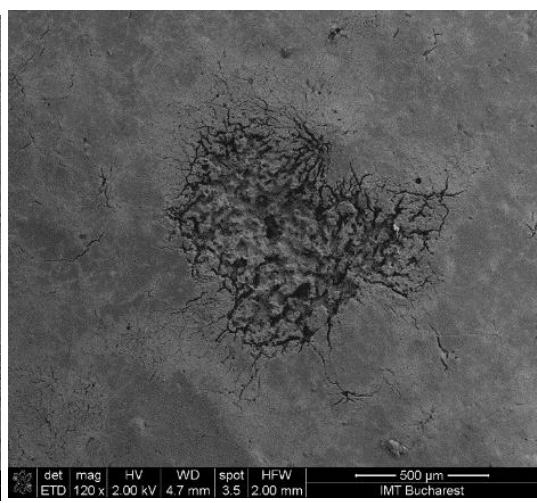

Figure 4B-PLA/HC10/Ag

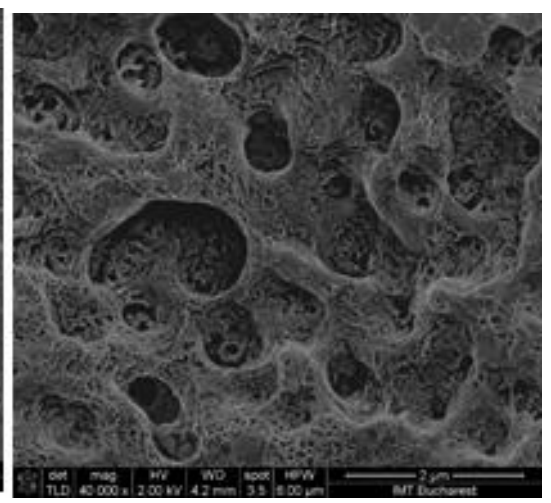

Figure 4C-PLA/HC10/Ag

Figure 4. SEM images for PLA/ATBC, PLA/HC10 and PLA/HC10/Ag blends. A- SEM images before exposure to active soil; $\mathrm{B}$ and $\mathrm{C}$-SEM images after 60 days exposure to active soil (x120 and x40000 magnitude)

\section{Conclusions}

From the biodegradation study by 60 days of exposure at active soil was observed for PLA and PLA/ATBC specimens that they were not susceptible to soil action and not show any weight loss. In the case of the blends based of hydrolysed collagen it was observed a low degree of degradation after 60 days, less than 5\% compared with more than 50\% degradation of the egg-carton positive sample (cardboard) and the degradation process was dependent of hydrolysed collagen content. 
The information provided by present paper can be important for future studies which are concerned with obtaining of biodegradable polymeric materials which could be used as food packaging, packaging and agricultural applications, when additional studies are required.

Acknowledgements. The work of PETRUTA PREDA has been funded by the Operational Programme Human Capital of the Ministry of European Funds through the Financial Agreement 51668/09.07.2019, SMIS code 124705. This work was supported by UEFISCDI in the Partnership Framework PN-III-P1-1.2-PCCDI-2017-0214 (Project No. 3PCCDI/2018).

\section{References}

1. KIM, D.Y., RHEE, Y.H., Biodegradation of microbial and synthetic polyesters by fungi. Applied in Microbiology and Biotechnology, 61, 2003, p. 300-308.

2. ABDELKEFI, A., ACHOUR, W., BEN, O.T., LADEB, S., TORJMAN, L., LAKHAL, A., BEN, H.A., HSAIRI, M., BEN, A.A., Use of heparin-coated central venous lines to prevent catheter-related bloodstream infection. The Journal of Supportive Oncology, 5, 2007, p. 273-278.

3. ABDELWAHAB, M.A., FLYNN, A., CHIOU, B.S., IMAM, S., ORTS, W., CHIELliNI, E., Thermal, mechanical and morphological characterization of plasticized PLA-PHB blends. Polymer Degradation and Stability, 97, no. 9, 2012, p. 1822-1828.

4. ELSAWy, M.A., KIM, K-H., PARK, J-W., DEEP, A., Hydrolytic degradation of polylactic acid (PLA) and its composites. Renewable and Sustainable Energy Reviews, 79, 2017, p. 1346-1352.

5. CASTRO-AGUIRRE, E., IÑIGUEZ-FRANCO, F., SAMSUDINB, H., FANG, X., AURAS, R., Poly(lactic acid)-Mass production, processing, industrial applications, and end of life. Advanced Drug Delivery Reviews, 2016, doi: 10.1016/j.addr.2016.03.010.

6. TOKIWA, Y., CALABIA, B.P., Biodegradability and biodegradation of poly(lactide). Applied in Microbiology and Biotechnology, 72, 2006, p. 244-251.

7. SMITH, R., Biodegradable polymers for industrial applications, publised by Woodhead Publishing Limited and CRC Press LLC, USA, 2005, p. 4.

8. LIU, L., FISHMAN, M.L., HICKS, K.B., LIU, C-K., Biodegradable Composites from Sugar Beet Pulp and Poly(lactic acid). Journal of Agricultural Food Chemistry, 53, 2005, p. 9017-9022.

9. ZHAO, R., TORLEY, P., HALLEY, P.J., Emerging biodegradable materials: starch- and proteinbased bio-nanocomposites. Journal of Material Sciences, 43, 2008, p. 3058-3071.

10. SHOGREN, R.L., DOANEB, W.M., GARLOTTA, D., LAWTONA, J.W., WILLETT, J.L., Biodegradation of starch/polylactic acid/poly(hydroxyester-ether) composite bars in soil. Polymer Degradation and Stability, 79, 2003, p. 405-411.

11. XIAO, L., WANG, B., YANG, G., GAUTHIER, M., Biomedical Science, Engineering and Technology, Prof. Dhanjoo N. Ghista (Ed.), Poly (Lactic Acid)-Based Biomaterials: Synthesis, Modification and Applications, 2012, p. 247-282.

12. Plastics - Evaluation of the action of microorganisms, SR EN ISO 846/2000

13. COCK, F., CUADRI, A.A., GARCIA-MORALES, M., PARTAL, P., Thermal, rheological and microstructural characterization of commercial biodegradable polyesters. Polymer Testing 32, 2013, p. 716-723.

14. CHANDRA, R., RUSTGI, R., Biodegradable Polymers. Progres in Polymer Science 23, 1998, p. 1273-1335.

15. RATTO, J.A., STENHOUSE, P.J., AUERBACH, M., MITCHELL, J., FARELL, R., Processing, performance and biodegradability of a thermoplastic aliphatic polyester/starch system. Polymer, 40, 1999, p. 6777-6788.

16. LUCAS, N., BIENAIME, C., BElloY, C., QUENEUDEC, M., SILVESTRE, F., NAVASAUCEDO J.E., Polymer biodegradation: Mechanisms and estimation techniques. Chemosphere, 73, 2008, p. 429-442. 
17. OHKITA, T., LEE, S.H., Thermal degradation and biodegradability of poly (lactic acid)/corn starch biocomposites. Journal of Applied Polymer Sciences, 100, 2006, p. 3009-3017.

18. VASILE, C., PAMFILA, D., RAPĂA, M., DARIE-NITA, R.N., MITELUT, A.C., POPAC, E.E., POPESCU, P.A., DRAGHICI, M.C., POPAC, M.E., Study of the soil burial degradation of some PLA/CS biocomposites. Composites Part B, 142, 2018, p. 251-262.

19. HARMAEN, A.S., KHALINA, A., AZOWA, I., HASSAN, M.A., TARMIAN, A., JAWAID, M., Thermal and Biodegradation Properties of Poly(lactic acid)/Fertilizer/Oil Palm Fibers Blends Biocomposites. Polymer Composite, 2014, doi: 10.1002/pc.22974.

20. YANG, X., YUAN, M., LI, W., ZHANG, G., Synthesis and Properties of Collagen/Polylactic Acid Blends. Journal of Applied Polymer Science, 94, no. 4, 2004, p. 1670-1675.

$\overline{\text { Manuscript received: } 18.03 .2020}$ 